\title{
Apolipoprotein E Gene Polymorphisms in Essential Hypertension: A Preliminary Study with Meta-analysis
}

\author{
Wisam $\mathrm{NI}^{\mathrm{a}}$, Norsidah $\mathrm{KZ}^{\mathrm{b}}$, Samsul $\mathrm{D}^{\mathrm{c}}$, Zamzila $\mathrm{A}^{\mathrm{d}}$, Rafidah $\mathrm{HM}{ }^{\mathrm{e}}$, Norlelawati $\mathrm{AT}^{\mathrm{d}}$ \\ aDepartment of Basic Medical Sciences for Nursing, Kulliyyahof Nursing, International Islamic University \\ Malaysia, KuantanPahang, Malaysia. \\ 'Department of Basic Medical Sciences, Kulliyyah of Medicine, International Islamic University Malaysia, \\ Kuantan Pahang, Malaysia. \\ 'Department of Community Medicine, Kulliyyah of Medicine, International Islamic University Malaysia, Kuantan \\ Pahang, Malaysia. \\ dDepartment of Pathology and Laboratory Medicine, Kulliyyahof Medicine, International Islamic University \\ Malaysia, KuantanPahang, Malaysia. \\ eFaculty of Medicine and Health Sciences, Universiti Sains Islam Malaysia, Nilai, Negeri Sembilan, Malaysia
}

\section{ABSTRACT}

Introduction: Essential hypertension is a multifactorial disease. Many experimental studies have elucidated the role of oxidative stress and atherosclerosis in the pathogenesis of essential hypertension. Apolipoprotein $E$ is a plasma protein that is found to have antioxidant properties, and it also protects against atherosclerosis. Interestingly, the biological function of apolipoprotein $\mathrm{E}$ is strongly affected by polymorphisms in its gene. Based on this evidence, our aim was to investigate the association of apolipoprotein $E$ gene polymorphisms with essential hypertension. Methods: This study was conducted on 70 hypertensive patients and 73 control participants recruited from the Balok governmental health clinic in Kuantan, Pahang. The polymerase chain reaction restriction fragment length polymorphism assay (PCR-RFLP) was used for determination of the apolipoprotein E genotype. Our results were also verified later by direct sequencing of the amplicons. Results: There was no significant association of apolipoprotein $E$ allele or genotype frequencies with hypertensive disease or blood pressure levels, although the $\varepsilon 4$ allele was slightly more frequent in the hypertensive patients than in the control group ( $\mathrm{OR}=1.055 ; 0.471-2.359, \mathrm{Cl} 95 \%)$. To improve the precision of the study and to settle the controversies among similar studies meta-analysis was performed; however it revealed a net nonsignificant association between the apolipoprotein $\mathcal{E} 4$ allele with essential hypertension in the combined population. Conclusion: Our data and the meta-analysis findings provide evidence that apolipoprotein $\mathrm{E}$ gene polymorphism has no direct significant association with hypertension.

KEYWORDS: Apolipoprotein E, essential hypertension, single nucleotide gene polymorphism.

\section{INTRODUCTION}

Hypertension is a major risk factor that accounts for significantly high morbidity and mortality because of complications such as stroke, myocardial infarction, congestive heart failure and end-stage renal disease. ${ }^{1}$ Essential hypertension is a heterogeneous complex disorder and patients are stratified by the complex interplay between environmental and genetic factors. ${ }^{2}$ It has been estimated that genetic factors account for as much as $70 \%$ of hypertension in families. ${ }^{3}$

Apolipoprotein $\mathrm{E}$ is a polymorphic multifunctional Corresponding author:

Wisam Nabeel Ibrahim

Department of Basic Medical sciences for Nursing,

Kulliyyah of Nursing, International Islamic University Malaysia

Level 2, Interdisplinary Block,

Kulliyyah of Science Biulding, Indera Mahkota Campus

25200, Kuantan, Pahang.

Tel: +6095704000 ext 7264

Fax: +6095133615

Mobile: +601129292372

Email:wisam@iium.edu.my protein that was first discovered in $1973 .{ }^{4}$ This protein is extremely important in lipid metabolism, as it facilitates the cellular uptake of low-density lipoprotein (LDL), thus promoting the clearance of chylomicron ruminants and very-low-density lipoprotein (VLDL). ${ }^{5}$ In addition, this protein has shown significant antioxidant properties in some experimental studies. ${ }^{6}$ Although the role of apolipoprotein E in lipid metabolism is already established, its association with essential hypertension is still debatable. Nevertheless, Davignon $^{7}$ has suggested that apolipoprotein E contributes to essential hypertension through its contributions in arteriosclerosis, oxidative stress, endothelial dysfunction and arterial smooth muscle spasm.

The function of apolipoprotein $E$ is highly regulated by its gene on chromosome 19 , which consists of four exons. ${ }^{8}$ The most important functional variability of this protein is explained by singlenucleotide polymorphisms (SNPs) within exon 4 of its gene. ${ }^{5}$ In exon 4 , the polymorphism occurs in codons 112 and 158, whereby the amino acid products of these codons are cysteine-cysteine, cysteine-arginine and arginine-arginine for epsilons $2(\mathcal{E} 2), 3(\mathcal{E} 3)$ and $4(\mathcal{E} 4)$, respectively. In most population studies, the $\mathcal{E} 3$ allele is the most common allele, with a frequency of approximately $78 \%$. Meanwhile, the $\varepsilon 4$ and $\varepsilon 2$ 
alleles are present in approximately $15 \%$ and $7 \%$ of the population, respectively. ${ }^{9,10}$ These three alleles are expressed co-dominantly to generate six different genotypes, whereas specific genotypes have been linked to certain disorders. ${ }^{8}$ It was found that homozygosity of the $\varepsilon 2$ allele is associated with type III hyperlipoproteinemia ${ }^{5}$ while homozygosity of the $\mathcal{E} 4$ allele is associated with increased risk for premature coronary artery disease and Alzheimer's disease., ${ }^{5,8}$

The aim of our study was to assess the association of apolipoprotein $\mathrm{E}$ gene polymorphism with essential hypertension in our sample of patients. At the same time, we decided to combine our results with other studies on Asian populations by means of a metaanalysis to verify and strengthen our results.

\section{MATERIALS AND METHODS}

\section{Study Population}

This study was conducted on a total of 143 participants. This sample achieved $91 \%$ power to detect an effective size of 0.6000 using a 2-degrees-of-freedom Chi-square test with a significance level (alpha) of $0.05000 .{ }^{11}$ Before commencing the study, ethical clearance was given by the International Islamic University Malaysia (IIUM) Research Ethics Committee (IREC), with additional permission obtained from the Balok governmental health clinic in Kuantan, Pahang. Full consent forms were signed by the participants after all of the necessary information about the study was clearly explained to them. The study included 70 hypertensive patients recruited on the basis of a diagnosis of hypertension. Patients with other confounders such as acute myocardial infarction, cerebrovascular accident, renal failure, congestive cardiac failure and hepatic failure were excluded from the study. In addition, we recruited 73 control participants who had never been diagnosed with hypertension and whose average blood pressure was lower than $140 / 90 \mathrm{mmHg}$. Questionnaires were used to record demographic factors such as age, gender and race.

After the measurement of systolic and diastolic blood pressures and upon completion of the questionnaire, blood samples were obtained and kept in EDTAcontaining tubes at a temperature of $-20{ }^{\circ} \mathrm{C}$ until further genetic testing.

\section{Genotyping}

All of the genotyping procedures were performed in the Molecular Laboratory, Kulliyyah of Medicine, IIUM. The DNA was extracted from the participant blood samples using a QIAmp extraction kit (Qiagen, Germany). The extracted DNA was further quantified and tested for quality using Biophotometer Plus (Eppendorff, USA). Apolipoprotein E gene polymorphism was assessed using the polymerase chain reaction restriction fragment length polymorphism assay (PCR-RFLP) as described previously. ${ }^{12}$ In brief, a 244-bp apolipoprotein E fragment was amplified by PCR with initial denaturation for 15 minutes, which was required for the activation of the HotStart ${ }^{\mathrm{TM}}$ (Qiagen,USA) Taq polymerase, followed by 39 cycles $\left(95{ }^{\circ} \mathrm{C}\right.$ for 15 seconds, $62{ }^{\circ} \mathrm{C}$ for 15 seconds and $72{ }^{\circ} \mathrm{C}$ for 15 seconds) with the primer pairs: forward 5"-TAAGCTTGG CAC GGC TGTCCAAGG A - "3 \&reverse 5"- ACA GAA TTC GCC CCG GCCTGG TAC ACT GCC - "3. The PCR reaction mixture (total volume $50 \mu \mathrm{L}$ ) contained approximately $50 \mathrm{ng}$ of genomic DNA, 1x amplification buffer (100 mM Tris- $\mathrm{HCl}, 50 \mathrm{mM} \mathrm{KCl}, \mathrm{pH} 8.4$ ), 10\% dimethyl sulfoxide (DMSO), $200 \mu \mathrm{M}$ of dNTPs, $0.5 \mu \mathrm{M}$ of each primer, 2.5 $\mathrm{mM}$ of $\mathrm{MgCl}$ and 2 units of HotStart ${ }^{\mathrm{TM}}$ (Qiagen, USA) Taq polymerase. The use of $10 \%$ DMSO significantly enhanced the amplification of the target amplicon. Molecular-grade $\mathrm{H}_{2} \mathrm{O}$ was added at the end to adjust the total volume of the PCR reaction mixture to $50 \mu \mathrm{l}$. The amplified fragment was then digested by the Hhal restriction enzyme for 4hours (Fermentas, USA). This enzyme recognizes and cuts the DNA at a specific nucleotide sequence of 5"- GCGC - “ $3 .{ }^{12}$ This enzyme produces different DNA fragments for each of the different genotypes through the SNPs in the apolipoprotein $\mathrm{E}$ gene, whereby the $\mathcal{E} 3$ allele nucleotide sequences of (TGC) and (CGC) in codons 112 and 158 , respectively, change to (TGC)-(TGC) and (CGC)(CGC) in the $\mathcal{E} 2$ and $\mathcal{E} 4$ alleles, respectively. These changes create a recognition site for the Hhal enzyme in the nucleotide sequence of the 158 and the 112 and 158 codons in the $\mathcal{E} 3$ and $\mathcal{E} 4$ alleles, respectively. Meanwhile, it demolishes the recognition site of these codons in the $\varepsilon 2$ allele. In addition to these two codons, there are four other non-polymorphic recognition sites (GCGC) in the apolipoprotein $E$ amplicon, which are found in each of the three alleles. ${ }^{12}$ Therefore, combining the above products in each of the six apolipoprotein E genotypes would give six unique combinations of DNA fragments as demonstrated in figure 1.

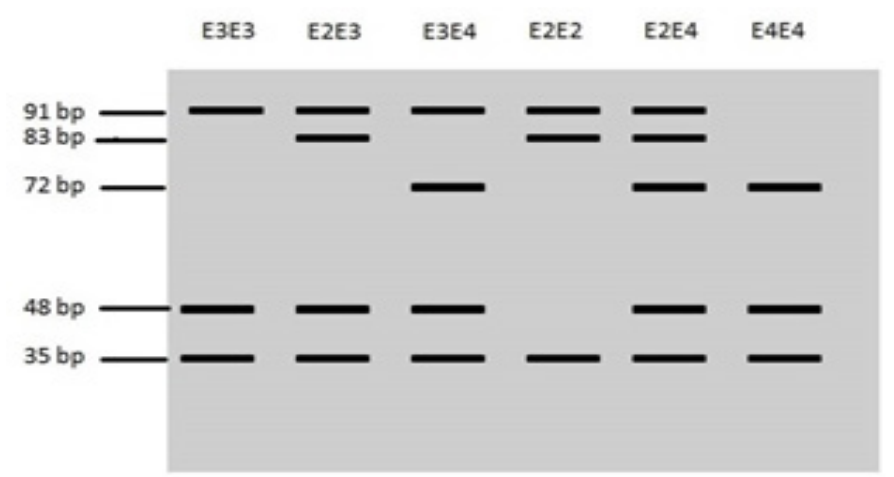

Figure 1: Schematic presentation of apolipoprotein E genotypes on agarose gel electrophoresis. 
Finally, the end products of Hhal enzyme digestion were resolved by electrophoresis on $5 \%$ agarose gel, as shown in figure 2 . The gels were stained using ethidium bromide (Bio-Rad, USA) before visualization with the UV camera (Bio-Rad, USA).

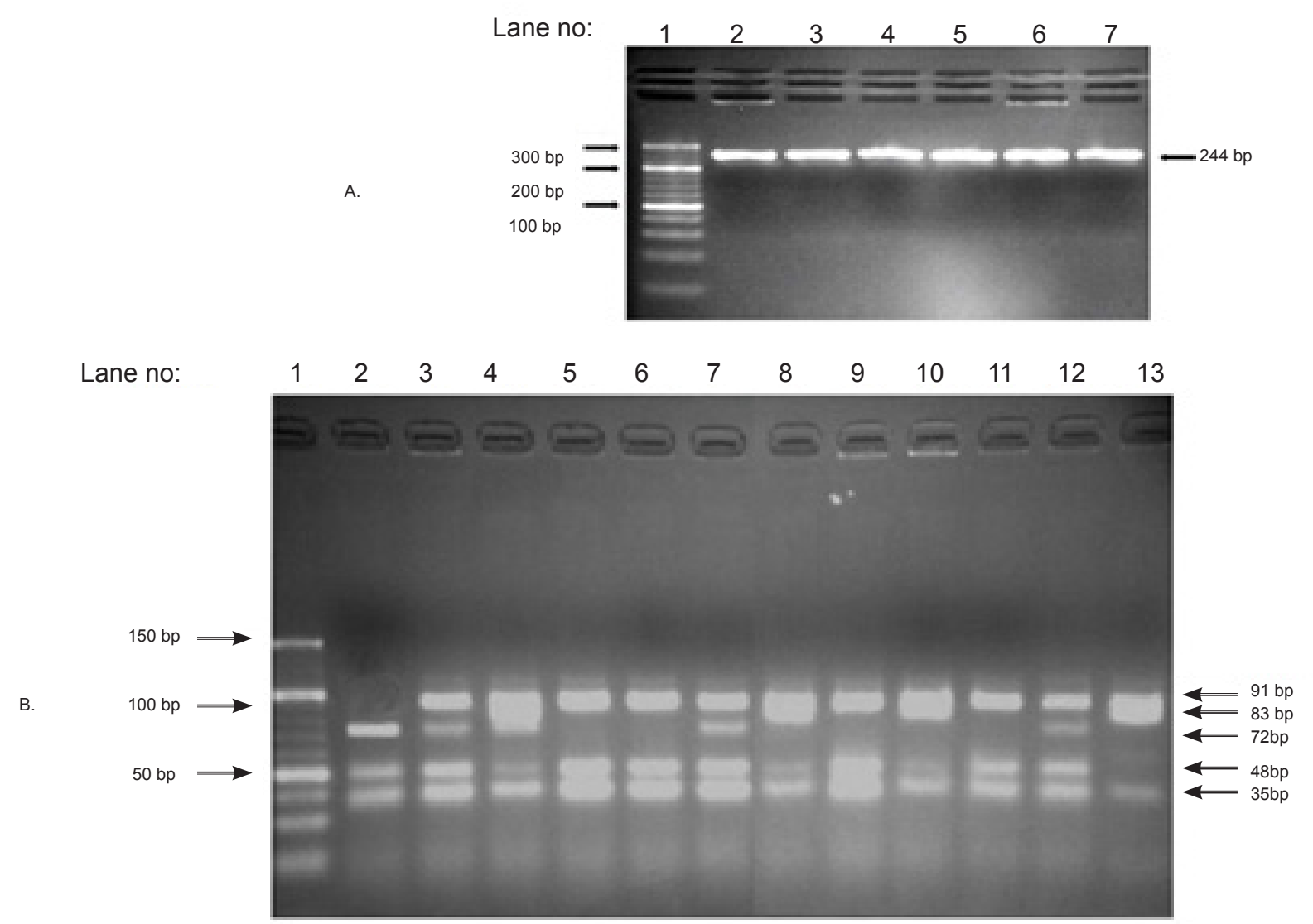

Figure 2. Agarose gel electrophoresis of apolipoprotein E. A: amplicon products (lane 1: 20bp DNA ladder; lanes 2-7: 244 bp PCR products). B: Hhal digested products (lane 1: 10 bp DNA ladder; lane 2: $\varepsilon 4 \varepsilon 4$ genotype; lanes 3, 7 and 12: $\varepsilon 3 \varepsilon 4$ genotype; lane 4: $\varepsilon 2 \varepsilon 4$ genotype; lanes 5, 6, 9 and 11: $\mathcal{E} \varepsilon 3$ genotype; lane 13: $\varepsilon 2 \varepsilon 2$ genotype; lanes 8 and 10: $\varepsilon 2 \varepsilon 3$ genotype).

\section{Validation of genotyping assay by direct sequencing}

After completing the genotyping of apolipoprotein $\mathrm{E}$ polymorphism in all of the samples, six randomly chosen PCR products from different genotypes were subjected to automated direct DNA sequencing using an ABI PRISM 3130 genetic analyser (Applied Biosystems, USA). The

A.

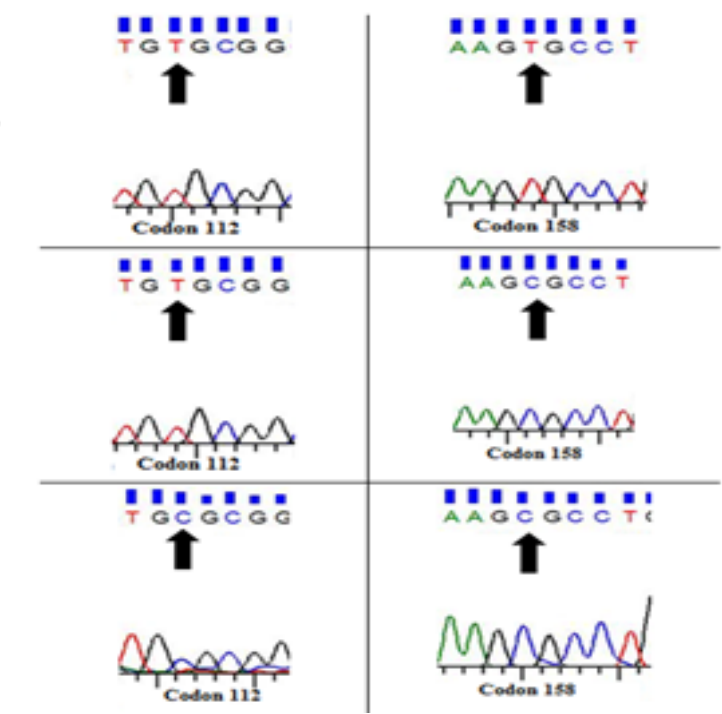

PCR products were purified using a QIAquick PCR purification kit (Qiagen, Germany), followed by sequencing using forward primer and the BigDye $®$ Terminator v3.1 Cycle Sequencing kit. The cycle-sequenced products were purified using the ethanol precipitation method. The reference sequence of the apolipoprotein $\mathrm{E}$ gene was obtained from the sequence provided. ${ }^{12}$

D.
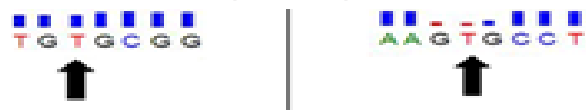

1

E.
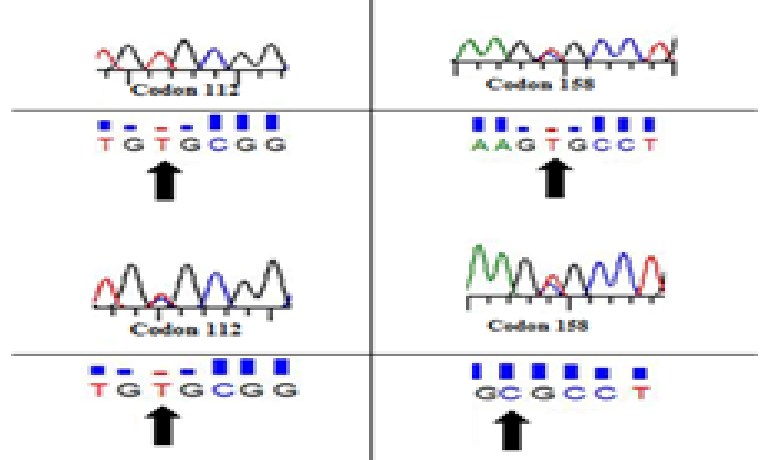

F.

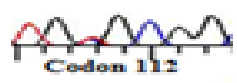

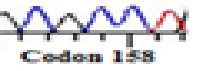

Figure 3: Direct nucleotide sequencing of selected PCR products. A: $\varepsilon 2 \varepsilon 2$ genotype, $B: \mathcal{E} 3 \mathcal{E} 3$ genotype, C: $\varepsilon 4 \varepsilon 4$ genotype, $D: \varepsilon 2 \varepsilon 3$ genotype, E: $\varepsilon 2 \varepsilon 4$ genotype and $F: \varepsilon 3 \varepsilon 4$ genotype. 


\section{Statistical analysis}

The statistical analysis was performed using SPSS software version 19.00. Microsoft Word and Excel were used to generate tables. Hardy-Weinberg equilibrium for the genotype distribution of every SNP was tested in the controls and the hypertensive cases by the Chi-square $(\mathrm{X} 2)$ test with $1 \mathrm{df}$. The allele frequencies and genotype distribution of apolipoprotein $\mathrm{E}$ were cross-tabulated between the hypertensive and control participants by the Chi-square $(\mathrm{X} 2)$ test. The association of apolipoprotein $\mathrm{E}$ genotypes with systolic and diastolic blood pressure was tested by ANOVA. Data were expressed as mean \pm standard deviation (SD) and a p-value of $<0.05$ was considered statistically significant.

\section{Meta-analysis}

It was stated in the Singapore Genome Variation Project ${ }^{13}$ that the genetic distribution of SNPs among the Malaysian and Chinese populations are almost the same. Based on this, a meta-analysis was performed by combining our results with sixteen Asian study populations of Chinese, Japanese, Korean and Asian American individuals to increase the sample size and power in order to measure the statistical effect. ${ }^{14}$ The analysis included the study populations ${ }^{15-28}$ listed in Table I.

From these studies, the odds ratios (ORs) have been calculated. The combination conveniently yielded a study of 3,224hypertensive cases and 4,472 control participants with more than $95 \%$ sampling power. The meta-analysis was performed using the Comprehensive Meta-analysis software version 3.3.070.

Table I: Selected studies for meta-analysis in Asian populations and their characteristics

\begin{tabular}{|c|c|c|c|c|c|}
\hline \multirow[b]{2}{*}{ Author } & \multirow[b]{2}{*}{ Country } & \multicolumn{2}{|l|}{ Cases } & \multicolumn{2}{|c|}{ Controls } \\
\hline & & $\mathcal{E} 4$ carriers & non- $\mathcal{E} 4$ carriers & $\mathcal{E} 4$ carriers & non- $\mathcal{E} 4$ carriers \\
\hline Cui et $\mathrm{al}^{15}$ & China & 15 & 105 & 15 & 105 \\
\hline Hu et $\mathrm{al}^{16}$ & China & 2 & 45 & 1 & 64 \\
\hline Imazu et $\mathrm{al}^{17}$ & Japan & 58 & 252 & 125 & 482 \\
\hline Katsuya et al ${ }^{18}$ & Japan & 256 & 1262 & 489 & 1990 \\
\hline Li et $\mathrm{al}^{19}$ & China & 6 & 88 & 5 & 97 \\
\hline Liu et $\mathrm{al}^{20}$ & China & 6 & 106 & 4 & 114 \\
\hline Niu et $\mathrm{al}^{21}$ & China & 104 & 165 & 26 & 210 \\
\hline Pan et $\mathrm{al}^{22}$ & China & 3 & 89 & 2 & 88 \\
\hline Peng et $\mathrm{al}^{23}$ & China & 7 & 88 & 0 & 105 \\
\hline Rong et $\mathrm{al}^{24}$ & China & 10 & 110 & 10 & 120 \\
\hline Um et $\mathrm{al}^{25}$ & Korea & 6 & 81 & 5 & 74 \\
\hline Wufuer et $\mathrm{al}^{26}$ & China & 45 & 25 & 22 & 33 \\
\hline Zhang et $\mathrm{al}^{27}$ & China & 2 & 106 & 1 & 116 \\
\hline Zhang et al $(\operatorname{Han})^{28}$ & China & 13 & 54 & 8 & 45 \\
\hline Zhang et al (Hui) ${ }^{28}$ & China & 17 & 50 & 6 & 58 \\
\hline Zhang et al (Tibet) ${ }^{28}$ & China & 13 & 35 & 10 & 42 \\
\hline
\end{tabular}

\section{RESULTS}

\section{Demographic analysis}

The mean age of the participants is shown in Table II. There was no significant difference in the mean age between the hypertensive and control participants $(p=0.84)$. The ethnic distribution of the participants was mainly of Malays (91\%), followed by
Chinese (9\%). There were no significant differences in the ethnic distributions between the patient and control groups $(p=0.67)$. In our study the female participants were significantly more in the patients group than in the controls (Table III); it was unlikely to effect the results of our study as there was no significant difference in genotype distribution among males and females $(p=0.38)$.

Table II: Age and blood pressure in patients and controls

\begin{tabular}{lllll}
\hline \hline Variables & $\begin{array}{l}\text { Patients }(\mathrm{n}=70) \\
\text { Mean }(\mathrm{SE})\end{array}$ & $\begin{array}{l}\text { Controls }(\mathrm{n}=73) \\
\text { Mean }(\mathrm{SE})\end{array}$ & $\mathrm{t}$ - value & $p$ value \\
Age (years) & $52.76(1.45)$ & $52.38(1.3)$ & 0.19 & 0.84 \\
$\begin{array}{l}\text { Blood pressure } \\
(\mathrm{mmHg})\end{array}$ & & & \\
& & & \\
$\begin{array}{l}\text { Systolic } \\
\text { Diastolic }\end{array}$ & $148.73(1.68)$ & $122.79(1.16)$ & 12.7 & $<0.001^{*}$ \\
& $91.61(1.1)$ & $79.10(0.72)$ & 9.5 & $<0.001^{*}$ \\
\hline
\end{tabular}

Independent t-test, $\mathrm{p}<0.05$ is taken as statistically significant at $95 \%$ confidence interval, *significant difference. 
Table III: Demographic data

\begin{tabular}{llll}
\hline Variables & $\begin{array}{l}\text { Patients } \\
(\mathrm{n}=70)\end{array}$ & $\begin{array}{l}\text { Controls }(\mathrm{n}=73) \\
\mathrm{N}(\%)\end{array}$ & $p$ value \\
\hline $\begin{array}{l}\text { Race } \\
\text { Malay }\end{array}$ & $63(90 \%)$ & $\begin{array}{l}67(95.7 \%) \\
6(4.3 \%)\end{array}$ & 0.67 \\
Chinese & $7(10 \%)$ & & \\
Gender & & & \\
Male & $24(34.3 \%)$ & $54(74 \%)$ & $<0.001^{*}$ \\
Female & $46(65.7 \%)$ & $19(26 \%)$ & \\
\hline
\end{tabular}

Chi-square test, $p<0.05$ is taken as statistically significant at $95 \%$

confidence interval, "significant difference.

Genotyping analysis

The genotyping of apolipoprotein $\mathrm{E}$ polymorphism was determined in a total of 143 participants. The participants' genetic data were presented as allele and genotype frequencies. There was no deviation of genotype frequencies from Hardy-Weinberg equilibrium in the experimental and control groups
(Table IV).

Finally the analysis of genotyping results has shown a non significant association of apolipoprotein $\mathrm{E}$ allele or genotype frequencies with hypertensive disease. Although the $\mathcal{E} 4$ allele was noted to be slightly more frequent in the hypertensive patients than in the control group (OR=1.055; 0.471-2.359, $\mathrm{Cl} 95 \%)$.

Table IV: Distribution of genotype and allele frequencies among patients and controls

\begin{tabular}{|c|c|c|c|}
\hline Marker & $\begin{array}{l}\text { Patients }(\mathrm{n}=70) \\
\mathrm{N} \text { (freq.) }\end{array}$ & $\begin{array}{l}\text { Controls ( } n=73 \text { ) } \\
N \text { (freq.) }\end{array}$ & $\mathrm{p}$-value \\
\hline
\end{tabular}

Apolipoprotein E genotypes

\begin{tabular}{|c|c|c|c|}
\hline$\varepsilon 3 \varepsilon 3$ & $48(0.686)$ & $48(0.658)$ & \multirow{6}{*}{0.143} \\
\hline$\varepsilon 2 \varepsilon 3$ & $4(0.057)$ & $11(0.151)$ & \\
\hline $\mathcal{E} 3 \mathcal{E} 4$ & $14(0.20)$ & $13(0.178)$ & \\
\hline$\varepsilon 2 \varepsilon 2$ & $3(0.043)$ & $0(0.00)$ & \\
\hline$\varepsilon 2 \varepsilon 4$ & $1(0.014)$ & $0(0.00)$ & \\
\hline$\varepsilon 4 \varepsilon 4$ & $0(0.00)$ & $1(0.014)$ & \\
\hline \multicolumn{4}{|c|}{ Alleles } \\
\hline$\varepsilon 2$ & $11(0.079)$ & $11(0.075)$ & \\
\hline$\varepsilon 3$ & $114(0.814)$ & $120(0.822)$ & 0.986 \\
\hline$\varepsilon 4$ & $15(0.107)$ & $15(0.103)$ & \\
\hline
\end{tabular}

Chi-square test; $p<0.05$ is taken as statistically significant at a $95 \%$ confidence interval. *significant difference

In addition one way ANOVA test was used to measure the association of the level of blood pressure with apolipoprotein $\mathrm{E}$ allele or genotype frequencies. However its result was also non-significant $(p=0.986$, 0.143 ) for apolipoprotein E alleles and genotypes respectively.

\section{Meta-analysis}

The meta-analysis for the estimates of combined ORs for the association of the apolipoprotein E $\mathcal{E} 4$ allele with hypertension observed a non-significant association as shown in Figure 4. In the analysis, five studies showed a significant association between apolipoprotein E $\quad \mathcal{E} 4$ and essential hypertension. $18,21,23,26,28$ Two studies on Japanese population samples found a reduced risk for hypertension among $\& 4$ carriers. ${ }^{17,18}$ On the contrary, as shown in Figure 4, thirteen studies found an increased risk; meanwhile, one study showed no risk for hypertension among $\mathcal{E} 4$ carriers among the patients and control participants (OR $1 ; 95 \% \mathrm{Cl}, 0.46-2.14) .{ }^{15}$

The $Q$ statistical test value indicated significant variability among the studies $(\mathrm{Q}=69, \mathrm{df}=16)$. In order to quantify the magnitude of heterogeneity, $\left.\right|^{2}$ was found to be significantly high $\left(I^{2}=76.7 \%, p<0.0001\right)$. And in order to investigate the influence of individual studies on the pooled ORs, every study was deleted each time in the meta-analysis. However, two studies showed undue influence on the pooled ORs. ${ }^{17,18}$ Moreover, the meta analysis showed a marked asymmetry among the studies which provides the evidence of this heterogeneity among the studies to be mainly due to publication bias. 


\begin{tabular}{|c|c|c|c|c|c|}
\hline \multirow[t]{2}{*}{ Stody name } & \multicolumn{5}{|c|}{ Statistics for each study } \\
\hline & $\begin{array}{l}\text { Odds } \\
\text { ratio }\end{array}$ & $\begin{array}{l}\text { Loner } \\
\text { limit }\end{array}$ & $\begin{array}{c}\text { Tpper } \\
\text { limit }\end{array}$ & Zvalue & p-Value \\
\hline Cui et at & 1.000 & 0.465 & 2.149 & 0.000 & 1.000 \\
\hline He ef al & 2.844 & 0.250 & 32.326 & 0.843 & 0.399 \\
\hline Imazu et al & 0.888 & 0.628 & 1.255 & .0 .675 & 0.500 \\
\hline Katsuya et al & 0.826 & 0.699 & 0.975 & .2 .253 & 0,024 \\
\hline Liet al & 1.198 & 0.349 & 4.032 & 0.274 & 0.784 \\
\hline Liv et al & 1.613 & 0.443 & 5.875 & 0.725 & 0.468 \\
\hline Nas et al & 5.091 & 3.164 & 8.192 & 6.706 & 0.000 \\
\hline Our study & 1.055 & 0.471 & 2.359 & 0.129 & 0.897 \\
\hline Pan et al & 1.483 & 0.242 & 9.093 & 0.426 & 0.670 \\
\hline Peng et al & 17.881 & 1.007 & 317.487 & 1.955 & 0.049 \\
\hline Reeg et al & 1.091 & 0.437 & 2.721 & 0.187 & 0.852 \\
\hline Umet al & 1.096 & 0.321 & 3.743 & 0.147 & 0.883 \\
\hline Wufuer et al & 2.700 & 1304 & 5.592 & 2.674 & 0.007 \\
\hline Zhang et al & 2.189 & 0.196 & 24.490 & 0.636 & 0.525 \\
\hline Zhant et al (Fian) & 1.354 & 0.516 & 3.556 & 0.615 & 0.538 \\
\hline Zhang et al (Hivi) & 3.287 & 1.204 & 8.976 & 2.321 & 0.020 \\
\hline Zhang et al (Tibet) & 1.560 & 0.610 & 3.958 & 0.929 & 0.353 \\
\hline Conbiacd & 1.079 & 0.949 & 1.226 & 1.160 & 0.245 \\
\hline
\end{tabular}

Odds ratio and $95 \% \mathrm{Cl}$

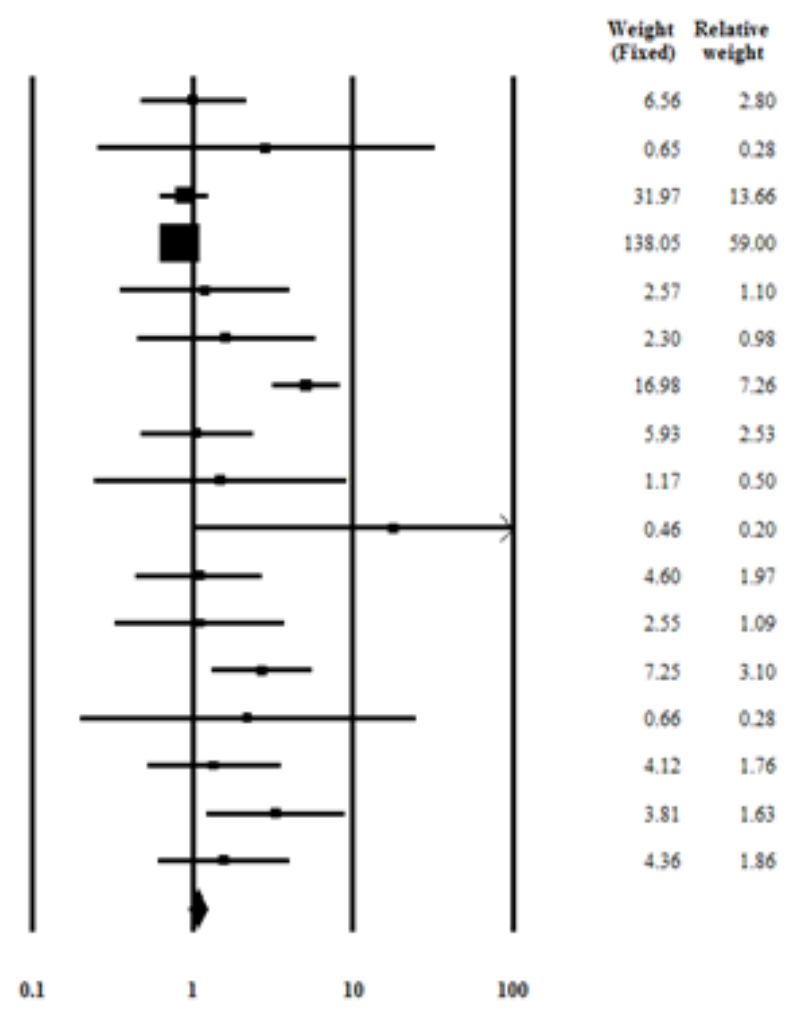

Figure 4. Forest plot for the odds of $\varepsilon 4$ allele in essential hypertension from the selected studies combined with our study.

\section{DISCUSSION}

To our knowledge, based on scrutinizing similar association studies in different populations, no existing study has addressed this issue in Malaysia. Our study found a non-significant association between essential hypertension and apolipoprotein $\mathrm{E}$ gene polymorphisms.

In our study, the estimated sample size was 70 participants for patients and control group according to Cohen's statistical tool. ${ }^{11}$ However, it is stated that genetic polymorphism association studies might need larger sample sizes to decrease the coefficient of variation of the estimated genetic distance. ${ }^{14}$

In the demographic data analysis there was significant difference of gender distribution among the two groups. However, the secondary analysis indicated that such an association with apolipoprotein E genotypes is absent for both males and females. The control participants in our study had the same ethnic distribution of apolipoprotein $E$ genotypes and consistent frequencies of genotypes and alleles compared to one Malaysian population study ${ }^{29}$ in which the $\varepsilon 3$ allele was present in the majority of participants, followed by the $\varepsilon 4$ and $\varepsilon 2$ alleles, respectively.

The fact that apolipoprotein $E$ is important in the protection against oxidative stress and atheroscle- rosis, ${ }^{7,} 30$ and with the understanding that individuals with essential hypertension are prone to oxidative stress ${ }^{31}$ and atherosclerosis, ${ }^{7,32}$ it is then hypothesized that defects within the apolipoprotein $\mathrm{E}$ gene may partly contribute to the development of essential hypertension.

The observations of association studies between the apolipoprotein $\mathrm{E}$ genotypes and hypertension in different populations show conflicting conclusions and inconsistent findings. Results from a number of studies involving Asian populations were consistent with ours. ${ }^{16,19,20,22,24,25,27,28}$ It is important to admit that most of these studies were conducted in small samples of populations, but similar findings were also noticed in a large population study, ${ }^{33}$ although it was conducted in a population of different ethnicity. On the other hand, some case-control studies have consistently described a significant association between the presence of the $\varepsilon 4$ allele and hypertension. $2,18,21,22,25,27$ For example, in two of these studies, one conducted in Japan by Katsuya $^{18}$ and the other by Imazu $^{17}$ on Hawaiian Japanese, both found a significant association between apolipoprotein $\mathrm{E}$ gene polymorphism and essential hypertension; however, the $\mathcal{E} 4$ allele was found to be a protective factor against hypertension $(\mathrm{OR}=0.83$, $0.88-95 \% \mathrm{Cl}[0.70-0.98,0.628-1.255$, respectively]). At the same time, in these two studies, the significant association was missing in elderly patients. ${ }^{18}$

Furthermore, the $\mathcal{E} 4$ allele was found to be sig- 
nificantly associated with high cholesterol, high triglycerides, high LDL and low HDL levels, which contradicts the fact that these findings predispose individuals to hypertension as mentioned above. These two studies carried a high weightage in the metaanalysis ( $73 \%$ combined). Interestingly, if both studies were excluded from the analysis, the net effect would become significant $(\mathrm{p}<0.01, \mathrm{OR} 2.1,95 \% \mathrm{Cl}, 1.6-2.7)$. However, pooling all the ORs from the mentioned studies revealed a net non-significant association between apolipoprotein E $\varepsilon 4$ and hypertension although, there was a marked evidence of publication bias that caused this significant heterogeneity among the studies.

Generally, because association studies are incompetent in proving causality, it is important to highlight the results from some functional studies in evidence for this pathophysiological dilemma. Experiments on genetically engineered mouse models (apolipoprotein knock-out mice) have shown some promising evidences. Where in some studies, there was significantly elevated blood pressure with abolition of the normal circadian blood pressure variations in the apolipoprotein E-/- mice compared with the age-matched control mice. ${ }^{34}$ In the same experiment, all of the apolipoprotein $\mathrm{E}-/$ - mice were also found to have hypercholesterolemia, which suggests the possibility that essential hypertension might be caused by the indirect effect of the dysfunctional apolipoprotein E through disturbances in its lipid-regulating function. However, the relationship between essential hypertension and the development of atherosclerosis is also actively debated because in some studies, certain markers of hypertension, such as epinephrine or angiotensin, are found to increase atherosclerosis in apolipoprotein E-/- mice. ${ }^{34}$ Meanwhile, a hypercholesterolemia mouse model are found to have an up regulated renin-angiotensin system, which is a known main confounder of essential hypertension..$^{35}$ It also essential to mention that in some experimental studies, no significant differences of blood pressure were found between apolipoprotein E -/- mice and age-matched controls. ${ }^{36}$

\section{CONCLUSION}

In summary, this study provides some evidence of the non-significant association between apolipoprotein $\mathrm{E}$ gene polymorphism and hypertension in a Malaysian sample. Accordingly, it is recommended to include more studies in the meta-analysis. More functional animal studies can help to finalize the role of the mentioned factors in the complex genetic/ environmental interplay.

\section{LIMITATIONS OF THE STUDY}

First, the participants were not randomly selected, so they could not represent the general population. Second, the relatively low number of subjects could have contributed to the non-significant association.

\section{ACKNOWLEDGMENT}

This study was supported by the Molecular Laboratory, Kulliyyah of Medicine \& Research Endowment Fund B (IIUM EDW B 11-134-0473) of International Islamic University Malaysia.

\section{CONFLICT OF INTEREST AND FUNDING}

The authors state that no conflict of interest exists.

\section{REFERENCES}

1. WHO. WHO/ISH Hypertension guidelines. Available at: http://www.who.int/ cardiovascular_diseases/guidelines/ hypertension/en/. Accessed February 2015.

2. Ruixing $Y$, Jinzhen $W$, Weixiong $L$, et al. The environmental and genetic evidence for the association of hyperlipidemia and hypertension. J Hypertens 2009;27:251-8.

3. Kaplan NM, Bakris GL, Forman JP. Genetic factors in the pathogenesis of essential hypertension. Update for patients. 2009.

4. Zannis VI, Breslow JL, Utermann G, et al. Proposed nomenclature of Apo $E$ isoproteins, Apo E genotypes and phenotypes. J Lipid Res 1982; 23:911.

5. Mahley RW, Weisgraber KH, Huang Y. Apolipoprotein E: structure determines function, from atherosclerosis to Alzheimer's disease to AIDS. J Lipid Res 2009; 50:S183-S8.

6. Shea TB, Rogers E, Ashline D, Ortiz D, Sheu M-S. Apolipoprotein E deficiency promotes increased oxidative stress and compensatory increases in antioxidants in brain tissue. Free Radic Biol Med 2002; 33:1115-20.

7. Davignon J. Apolipoprotéine $\mathrm{E}$, une molécule polymorphe et pléiotrope-Première partie: Rôle dans l'athérosclérose et au-delà. Sang Thrombose Vaisseaux 2002;14:39-58.

8. Leduc V, Domenger D, De Beaumont L, et al. Function and comorbidities of apolipoprotein e in Alzheimer's disease. Int J Alzheimers Dis 2011; 2011.

9. Hatters DM, Peters-Libeu CA, Weisgraber KH. Apolipoprotein E structure: insights into function. Trends Biochem Sci 2006; 31:445-54.

10. Eisenberg DT, Kuzawa CW, Hayes MG. Worldwide allele frequencies of the human apolipoprotein E gene: climate, local adaptations, and evolutionary history. Am J Phys Anthropol 2010;143:100-11.

11. Cohen J. Statistical power analysis for the behavioral sciences: Academic press; 2013.

12. Hixson JE, Vernier DT. Restriction isotyping of human apolipoprotein $\mathrm{E}$ by gene amplification and cleavage with Hhal. J Lipid Res 1990; 31:545-8.

13. Teo $Y$-Y, Sim X, Ong RT, et al. Singapore Genome Variation Project: a haplotype map of three Southeast Asian populations. Genome Research 2009; 19:2154-62. 
14. Kalinowski S. Do polymorphic loci require large sample sizes to estimate genetic distances? Heredity 2005; 94:33-6.

15. Guofang C ZM, Bingxian H. Relationships between polymorphism of apoE gene and hypertension in the Han ethnics of China. Chin J Clin Rehab 2003; 7:2545-6.

16. Caiyou H CZ, Zeping L, Ze Y, Jiying L, Yong W. The study of relation between blood pressure and apolipoprotein $\mathrm{E}$ genotypes in long-lived elderly in Bama area of Guangxi. Chin J Geriatr Heart Brain Vessel Dis 2007; 9:11-3.

17. Imazu M, Yamamoto H, Toyofuku M, et al. Association of apolipoprotein E phenotype with hypertension in Japanese-Americans: data from the Hawaii-Los Angeles-Hiroshima Study. Hypertension Res 2001; 24:523-9.

18. Katsuya T, Baba S, Ishikawa K, et al. Epsilon 4 allele of apolipoprotein $\mathrm{E}$ gene associates with lower blood pressure in young Japanese subjects: the Suita Study. J Hypertension 2002; 20:2017-21.

19. Li X, Du Y, Du Y, Huang X. Association of apolipoprotein $\mathrm{E}$ gene polymorphism with essential hypertension and its complications. Clin Exp Med 2003; 2:175-9.

20. Yingwang $L S Z, A n Z$, Sai N. Effect of apolipoprotein $\mathrm{E}$ gene polymorphism on lipid and essential hypertension. Chin J Arterioscler 2002; 10:517-20.

21. Niu W, Guo X, Su Y, Qiu C. Apolipoprotein E and low-density lipoprotein receptor gene polymorphisms in dyslipidemias-associated essential hypertension. Journal of human hypertension 2007; 21:337-9.

22. Min P JZ, Li L, Haiyan P, Huimin W, Shu L et al. Association of Apolipoprotein E with essential hypertension, NIDDM and coronary heart disease in Chinese population. Chin Synth Med 2002;3:1-3.

23. Wen P SG, Wei L, Xiaohong Z. Apolipoprotein E gene polymorphism and hypertension. J Chin Gen Pract 2003;2:14-5.

24. Chunli R YP, Meixia L, Ruyi L, Xue G. Analysis of apolipoprotein $\mathrm{E}$ gene polymorphism in hypertensive patients. Shandong Med J 2007; 47:29-30.

25. Um J-Y, Hwang C-Y, Hwang W-J, Kang S-D, Do $\mathrm{K}-\mathrm{R}$, Cho J-J, et al. Association between iris constitution and apolipoprotein e gene polymorphism in hypertensives. Journal of Alternative \& Complementary Medicine 2004; 10:1101-5.

26. Hamulati W AY, Yilihamujiang S. Relationship between ApoE gene polymorphism and patients of hypertension in Uyghur. Chin J Immunol 2003; 19:108-10.

27. Zhimian Z HG, Qing S, Lihua F. Clinical study of relationship between ApoE gene polymorphism and hypertension in aged. Acta Academiae Medicinae Shandong 2000; 38:173-6.

28. Weize $Z \mathrm{XL}$, Yongqing $\mathrm{C}$, Ling $\mathrm{M}$, et al. Relationship between apolipoprotein $\mathrm{E}$ gene polymorphism and essential hypertension in Han, Tibetan and Hui population in high altitude area. Chin Circ J 2007; 22:263-6.

29. Seet Wan Tai. JTaSt. Correlation between Apolopoprotein E genotype and Cholesterol levels in Malays. Chinese and Indian population in Malaysia. Seminar Penyelidikan jangka pendek 2003; (V to F).Unpublished.

30. Tomás $M$, Latorre $G$, Sentí M, Marrugat J. The antioxidant function of high density lipoproteins: a new paradigm in atherosclerosis. Revista Española de Cardiología (English Edition) 2004; 57:557-69.

31. Harrison DG, Gongora MC. Oxidative stress and hypertension. Med Clin North Am 2009; 93:62135.

32. Vasquez EC, Peotta VA, Gava AL, Pereira T, Meyrelles SS. Cardiac and vascular phenotypes in the apolipoprotein E-deficient mouse. J Biomed Sci 2012; 19:1186.

33. Fuzikawa AK, Peixoto S, Taufer M, Moriguchi EH, Lima-Costa MF. Association of ApoE polymorphisms with prevalent hypertension in 1406 older adults: the Bambui Health Aging Study (BHAS). Brazilian Journal of Medical and Biological Research 2008; 41:89-94.

34. Yang R, Powell-Braxton L, Ogaoawara AK, et al. Hypertension and endothelial dysfunction in apolipoprotein E knockout mice. Arteriosclerosis, thrombosis, and vascular biology 1999; 19:2762-8.

35. Wang Z, Peng X. Pathogenesis of essential hypertension: development of a 4-dimensional model. Hypothesis 2013;1:7.

36. d'Uscio LV, Barton M, Shaw S, Lüscher TF. Chronic ETA receptor blockade prevents endothelial dysfunction of small arteries in apolipoprotein E-deficient mice. Cardiovascular Research 2002; 53:487-95. 